\title{
Protriptyline in the treatment of sleep apnoea
}

\author{
WA CONWAY, F ZORICK, P PICCIONE, T ROTH
}

From the Department of Medicine, Pulmonary Medicine Division and Sleep Disorders Center, Henry Ford Hospital, Detroit, Michigan, USA

ABSTRACT Nine patients with obstructive sleep apnoea were treated with 5 to $20 \mathrm{mg}$ of protriptyline each night for two to 18 months. In four patients, there was dramatic, sustained improvement in symptoms and measured sleep quality and apnoea frequency and duration. There was no improvement in two patients and three developed intolerable side-effects preventing adequate treatment. Apnoea frequency was the only apparent predictor of responsiveness. Those with fewer than 30 episodes of apnoea per hour consistently improved. Only two of four patients with more than 60 episodes per hour improved. These results provide additional evidence that a carefully monitored trial of protriptyline may benefit selected patients with mild to moderate obstructive sleep apnoea.

Obstructive sleep apnoea is characterised by intermittent episodes of upper airway obstruction during sleep. ${ }^{1}$ It is caused by pharyngeal collapse from hypotonia of the airway musculature, with or without anatomical obstruction, ${ }^{2} 3$ and it can produce somnolence and cardiopulmonary complications that are disabling and even life-threatening. Although tracheostomy to bypass the site of the obstruction has been a consistently effective form of therapy, ${ }^{45}$ its use is limited because of long-term complications and its inherent invasiveness. ${ }^{6}$ Moreover, its risks outweigh the benefits in individuals with less severe disease. Consequently, alternative

Address for reprint requests: Dr WA Conway, Division of Pulmonary Medicine, Henry Ford Hospital, 2799 West Grand Boulevard, Detroit, Michigan 48202, USA. approaches to therapy are needed.

Protriptyline, a nonsedating tricyclic antidepressant, has been used to improve the drowsiness and cataplexy associated with narcolepsy. Because patients with narcolepsy occasionally have concurrent sleep apnoea, ${ }^{1}$ we and others ${ }^{7}$ have observed that when narcoleptics are treated with protriptyline, their apnoeic episodes are fewer and shorter. This report provides additional evidence that some patients with upper airway sleep apnoea improve after treatment with protriptyline.

\section{Methods}

Our trial was carried out with nine patients who had upper airway sleep apnoea (table 1). It began for-

Table 1 Clinical characteristics

\begin{tabular}{|c|c|c|c|c|c|}
\hline Patient & Age & $\%$ ideal weight* & $\mathrm{PaO}_{2}(k P a)$ & $\mathrm{PaCO}_{2}(k P a)$ & Other conditions \\
\hline 1 & 21 & 153 & $11 \cdot 9$ & $5 \cdot 2$ & \\
\hline 2 & 48 & 140 & $7 \cdot 4$ & $4 \cdot 8$ & $\begin{array}{l}\text { Narcolepsy } \\
\text { Right ventricular } \\
\text { hypertrophy } \\
\text { Polycythaemia } \\
\text { COPD (FEV } / \text { FVC: } 67 \% \text { ) }\end{array}$ \\
\hline 3 & 37 & 98 & $10 \cdot 8$ & $4 \cdot 4$ & $\begin{array}{l}\text { Uvulopalatopharyngoplasty } \\
\text { and Septoplasty }\end{array}$ \\
\hline 4 & 54 & 160 & $8 \cdot 2$ & $5 \cdot 3$ & $\begin{array}{l}\text { Hypertension } \\
\text { COPD (FEV } 1 / \text { FVC: } 74 \%)\end{array}$ \\
\hline 5 & 32 & 161 & $9 \cdot 8$ & $6 \cdot 0$ & Hypertension \\
\hline 6 & 56 & 113 & $10 \cdot 1$ & $4 \cdot 6$ & \\
\hline 7 & 51 & 100 & $9 \cdot 8$ & $4 \cdot 3$ & $\begin{array}{l}\text { Prostatic hypertrophy } \\
\text { Hypertension } \\
\text { Hypothyroid on therapy } \\
\text { Diabetes }\end{array}$ \\
\hline 8 & 56 & 170 & $9 \cdot 0$ & $3 \cdot 5$ & Hypertension \\
\hline 9 & 47 & 186 & $10 \cdot 6$ & $4 \cdot 5$ & Asthma \\
\hline
\end{tabular}

*From Society of Actuaries, Build and Blood Pressure Study, vol I, Chicago, 1959, page 16. 
tuitously with our observation that the apnoea of patient 2 improved when he was treated with protriptyline for narcolepsy. As a result, we then used this drug to treat eight other patients with upper airway sleep apnoea. They were selected either because they had symptomatic obstructive sleep apnoea without evidence of cor pulmonale, serious arrhythmia or hypercapneic respiratory failure, or because they had complications (patient 2) but refused tracheostomy. All were informed of the possible adverse effects of protriptyline and consented to a trial of this medication.

Our patients were all men from 21 to 56 years of age (table 1). Six were obese and had reached their peak adult weight after many unsuccessful attempts to lose weight. Systemic hypertension was common, and two had chronic obstructive lung disease. Patient 3 had a septoplasty and uvulopalatopharyngoplasty ${ }^{8}$ but continued to have severe sleep apnoea. Only patient 2 had serious complications-namely, right ventricular hypertrophy and polycythaemia. None had otolaryngological abnormalities. In all patients, apnoea was predominately of the obstructive or mixed type. Their symptoms had been present for one to three years and were typical of sleep apnoea, including excessive daytime drowsiness, sleep disruption with frequent arousal and body movements, loud, intermittent snoring, and morning headaches.

Initial evaluation included a history and physical examination, chest radiograph, electrocardiogram, 24-hour dynamic cardiogram, spirometry, arterial blood gases, electrolytes, serum thyroxin level, and indirect laryngoscopy. We obtained a polysomnograph for a complete night's sleep using standard techniques for sleep stage identification and electrocardiographic monitoring. ${ }^{9}$ Respiration was monitored with a thermistor at the nose and mouth to detect airflow and a thoraco-abdominal strain gauge to detect respiratory effort. We used a HewlettPackard ear oximeter to record haemoglobin saturation in six patients. Apnoea was defined as cessation of airflow for longer than 10 seconds; upper airway obstruction as episodes of apnoea with persistent or increased strain gauge activity; and central apnoea as absence of strain gauge activity with cessation of airflow. Awakenings were defined as EEG arousal that lasted longer than 30 seconds. The amount of time the haemoglobin saturation was less than $85 \%$ was scored and expressed as a percent of total sleep time.

We started protriptyline treatment with $5 \mathrm{mg}$ an hour before sleep, then increased the dosage by $5 \mathrm{mg}$ every other week until symptoms improved or a peak dose of $20 \mathrm{mg}$ was reached. We monitored responses with polysomnography and dynamic cardiograms after two to four months of treatment then every six months thereafter.

\section{Results}

\section{SUBJECTIVE RESPONSE}

Four of the nine patients clearly improved after treatment with protriptyline (table 2). Within two weeks, they reported that they were sleeping better with less snoring and daytime drowsiness. Patient 1 was no longer failing at school and two other patients returned to work. In patient 4 , polycythaemia resolved with haemoglobin decreasing from $19.2 \mathrm{~g}$ to $16.5 \mathrm{~g}$. However, two patients did not report any significant improvement in their symptoms. Three patients discontinued the medication because of side-effects, and follow-up polysomnography on them was not available.

\section{SLEEP EVALUATION}

The patients' subjective rating of change corresponds well with the physiological response as determined by polysomnography. The frequency of apnoea fell dramatically in four from an average of 40 to five episodes per hour after treatment. Apnoea frequency was unchanged in two. Patients with severe apnoea tended to have a poor response; of four patients with more than 60 episodes of apnoea per hour of sleep,

Table 2 Results of protriptyline in patients with upper airway sleep apnoea

\begin{tabular}{|c|c|c|c|c|c|c|c|c|c|c|c|c|c|c|c|c|c|c|c|}
\hline \multirow[t]{3}{*}{ Patient } & \multirow{3}{*}{$\begin{array}{l}\text { Weight } \\
\text { change } \\
(\mathrm{kg})\end{array}$} & \multirow{3}{*}{$\begin{array}{l}\text { Subjective } \\
\text { improvernent } \\
\text { of } \\
\text { somnolence } \\
(\%)\end{array}$} & \multirow{2}{*}{\multicolumn{2}{|c|}{$\begin{array}{l}\text { Total } \\
\text { sleep time } \\
\text { (minutes) }\end{array}$}} & \multicolumn{6}{|c|}{ Apnoea } & \multicolumn{6}{|c|}{ Sleep } & \multirow{2}{*}{\multicolumn{2}{|c|}{$\begin{array}{l}\text { o Total } \\
\text { sleep time } \\
\text { saturation }\end{array}$}} & \\
\hline & & & & & \multicolumn{2}{|c|}{$\begin{array}{l}\text { Frequency/ } \\
\text { hour }\end{array}$} & \multicolumn{2}{|c|}{$\begin{array}{l}\text { Mean } \\
\text { duration }\end{array}$} & \multicolumn{2}{|c|}{$\begin{array}{l}\% \text { Central } \\
\text { type }\end{array}$} & \multicolumn{2}{|c|}{$\%$ Stage I } & \multicolumn{2}{|c|}{$\% R E M$} & \multicolumn{2}{|c|}{ Awakenings } & & & ? \\
\hline & & & Pre & Post & Pre & Post & Pre & Post & Pre & Post & Pre & Post & Pre & Post & Pre & Post & Pre & Po: $t$ & $\stackrel{0}{E}$ \\
\hline 1 & -8 & 100 & 431 & 416 & 60 & 3 & 25 & 17 & 10 & 70 & 31 & 14 & 17 & 7 & 1 & 2 & 12 & 0 & $\omega$ \\
\hline 2 & -10 & 80 & 396 & 298 & 30 & 2 & 24 & 15 & 10 & 90 & 20 & 14 & 7 & 4 & 13 & 4 & - & $\ldots$ & 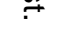 \\
\hline 3 & 0 & 80 & 366 & 354 & 63 & 13 & 20 & 17 & 0 & 0 & 33 & 16 & 9 & 6 & 13 & 6 & 8 & 0 & T \\
\hline 4 & 4 & 70 & 276 & 224 & 9 & 2 & 12 & 30 & 0 & 0 & 11 & 18 & 5 & 21 & 16 & 7 & 7 & 7 & $\overline{0}$ \\
\hline 5 & -8 & 0 & 314 & 226 & 85 & 93 & 24 & 15 & 10 & 10 & 58 & 54 & 14 & 4 & 26 & 30 & 58 & 73 & $\overrightarrow{C D}$ \\
\hline 6 & 0 & 20 & 399 & 350 & 60 & 50 & 30 & 21 & 10 & 10 & 19 & 31 & 14 & 1 & 6 & 5 & $1 \cdot 5$ & 0 & อั \\
\hline 7 & .- & - & 435 & - & 56 & - & 39 & - & 0 & - & 47 & $\ldots$ & 9 & - & 9 & $-\ldots$ & $\ldots$ & - & (D) \\
\hline 8 & - & - & 367 & - & 75 & $\longrightarrow$ & 21 & - & 30 & - & 57 & - & 14 & $\ldots$ & 9 & $\cdots$ & 4 & & 으 \\
\hline 9 & - & - & 287 & - & 59 & - & 22 & - & 0 & - & 52 & - & 3 & - & 14 & - & - & - & ס \\
\hline
\end{tabular}


only two improved. The pattern of apnoea changed in two of the responders in whom nearly all apnoea after treatment was central in origin. The mean duration of apnoea decreased by $30 \%$ in four of six patients, but was unchanged or increased in patients 3 and 4.

Because of frequent arousals associated with the apnoeic episodes, the proportion of stage I sleep ("light sleep") increases in sleep apnoea. Sleep quality improved in all four of the protriptyline responders with fewer awakenings (11 versus five) and decreased stage I sleep from an average of $24 \%$ to $15 \%$ (normal $=3 \%$ to $11 \%$ ). Although stage $I$ sleep rose slightly in patient 4 , stage III-IV sleep increased from $6 \%$ to $19 \%$. Like all tricyclic antidepressants, protriptyline caused a small decline in the amount of REM sleep in five of six patients.

Since oximetry was available for only three of the responders, the impact of improved ventilation on nocturnal hypoxia is difficult to assess in this group. In two patients, the portion of sleep time during which saturation was less than $85 \%$ improved dramatically, but desaturation was unchanged in patient 4 possibly because of his associated lung disease.

The effect of any intervention in sleep apnoea needs to be related to weight change. Since it takes several weeks to titrate a dose and observe a peak response to protriptyline, some weight change occurred in many of our patients, ranging from a gain of $8 \mathrm{~kg}$ to a loss of $10 \mathrm{~kg}$. It is unlikely that this minimal weight change affected our results. Moreover, symptomatic response occurred within two weeks of treatment.

\section{SIDE-EFFECTS AND OUTCOME}

In three patients, protriptyline was discontinued within two weeks because of side-effects (table 3 ). In one case, the anticholinergic properties of protriptyline produced marked urinary retention. Another patient developed a pruritic rash which recurred on rechallenge with the drug, and the third complained of confusion and ataxia and stopped

\section{Table 3 Side-effects and outcome}

\begin{tabular}{ll}
\hline Patient & Outcome \\
\hline 1 & Protriptyline $\times 15 \mathrm{mo}$ \\
2 & Apnoea $20 / \mathrm{hr} ; 25 \mathrm{~s}$ duration \\
Protriptyline $\times 18 \mathrm{mo}$ \\
3 & Apnoea $6 / \mathrm{hr} ; 17 \mathrm{~s}$ duration \\
4 & Protriptyline $\times 2 \mathrm{mo}$ \\
5 & Protriptyline $\times 8 \mathrm{mo}$ \\
6 & Apnoea $3 / \mathrm{hr} ; 20 \mathrm{~s}$ duration \\
7 & Tracheostomy \\
8 & Refused tracheostomy \\
9 & Urinary retention \\
\hline
\end{tabular}

taking the medication after one week. There was no clinical evidence of heart failure after protriptyline had been administered, and dynamic ECG monitoring did not reveal an increase in the frequency of ectopic beats or new arrhythmias. Most patients complained of dry mouth, which responded to symptomatic treatment. Three of four patients who responded to protriptyline have been treated for eight to 18 months with good symptomatic response. However, in two patients who have been treated for 12 months, polysomnography has demonstrated an increase in apnoea frequency and a decrease in the quality of sleep indicating a possible decreasing effectiveness with time.

\section{Discussion}

Permanent tracheostomy is the mainstay of treatment in severe upper airway sleep apnoea. ${ }^{4}$ This procedure bypasses the functional upper airway obstruction and uniformly reduces the symptoms and complications. However, because it results in significant morbidity, ${ }^{6}$ it cannot be recommended for patients with milder forms of this disease. Other surgical approaches to enlarge the nasal passages or nasopharynx have been successful in a few patients, ${ }^{5}$ mostly children whose enlarged tonsils and adenoids are a common cause of upper airway obstruction. In the adult, however, nasal septoplasty or tonsillectomy have rarely been successful. Other otolaryngological procedures, such as uvulopalatopharyngoplasty, offer promise but require further investigation. ${ }^{8}$

The search for medical treatments occurs on several fronts. Weight loss is generally recognised to be beneficial, although there are no reports detailing its efficacy. Moreover, this is an elusive goal since massively obese patients usually do not lose weight permanently. Respiratory stimulants such as xanthines and medroxyprogesterone, while usually improving daytime ventilation, ${ }^{10}$ have had disappointing effects on apnoea during sleep..$^{11} 12$ Finally, tricyclic antidepressants have been inconsistently effective in the treatment of obstructive sleep apnoea. Chlorimipramine, a sedating tricyclic, was felt to be beneficial in some case reports ${ }^{13} 14$ but of no value in another. ${ }^{16}$ In one series using protriptyline, a nonsedating tricyclic, there was sustained improvement in eight of 14 patients with upper airway sleep apnoea. ${ }^{15}$

In our experience, four of nine patients showed a dramatic objective improvement in sleep quality and ventilation as well as reporting less daytime somnolence. In these four, the number of apnoeic episodes per hour of recorded sleep dropped, and the duration of individual episodes was shorter. The quality of 
sleep also improved as illustrated by the reduction in stage I sleep and in awakenings from sleep. While oxygenation tended to improve, this tendency requires further documentation.

Of the remaining five patients, two (patients 5 and 6) did not respond to the drug therapy. Their only remarkable characteristic was an extremely high frequency of apnoea. In fact, in the four patients with the most severe apnoea (more than 60 episodes per hour) only two improved.

In the other three patients, the side-effects of protriptyline limited its effectiveness. Although our patients did not experience cardiac side-effects, they have been reported in three of 14 patients by Clark et al. ${ }^{15}$ Otherwise, Clark's experience appears to be similar to ours, with eight of 14 patients showing effective improvement of upper airway sleep apnoea. It is difficult to compare the groups precisely, since Clark et al reported apnoea frequency as a percent of total sleep time and did not provide information on weight change. However, only two of their six patients with the most severe apnoea (greater than $17 \%$ of total sleep time) responded sufficiently to avoid tracheostomy. Their patients who responded did so generally with a dramatic drop in apnoea frequency to less than $1 \%$ of total sleep time. In both series, patients with narcolepsy improved. However, since they all had mild to moderate apnoea, this response may be related to apnoea frequency. Thus, it would appear that patients with very severe apnoea did not respond well to protriptyline and that sideeffects usually ascribed to tricyclic antidepressants will prevent sustained treatment in some patients.

The action of protriptyline is most likely mediated in the central nervous system, so that improvement in the functional innervation of the upper airway musculature may be produced. The marked decrease in obstructive apnoea with retention of central apnoea in some patients, as well as the decrease in apnoea duration would support this possibility. This action is not caused by the drug's anticholinergic property since atropine-like drugs are not effective in upper airway sleep apnoea. ${ }^{17}$ However, it may possibly be caused by the effect of tricyclics in blocking the "amine pump" located in the presynaptic nerve endings. Since this blocking action is not the same for all tricyclics, protriptyline's unique effectiveness may be the result of a stronger blockade of the "amine pump" for norepinephrine than for serotonin. ${ }^{18}$

There appears to be a clear-cut differential response to protriptyline with some patients not responding well and other responding dramatically. This is difficult to explain since we do not know how this drug affects upper airway sleep apnoea. Clinically, there are no apparent differences between those who did and those who did not respond except for the frequency of apnoea. Nor would the minimal changes in weight and proportion of REM sleep in our patients account for the varied responsiveness to protriptyline. If the sleep apnoea syndrome has several causes, differing neurochemical abnormalities may be responsible for impaired upper airway control during sleep and the difference in drug responsiveness. On the other hand, since the disease appears to be produced by both anatomical and neuromuscular factors, it is possible that the nonresponders had more severe anatomical changes, such as redundant oropharyngeal mucosa, which contributed to the frequent apnoea and exceeded the threshold beyond which pharmacological interventions to improve airway function could be effective. The dramatic response in patient 3 after uvulopalatopnaryngoplasty was performed to enlarge the oropharyngeal airway would support this view. Finally, since the dose-response curve for protriptyline has not been determined, larger doses might have induced some responsiveness in patients with more severe apnoea.

Additional studies are clearly needed to understand the exact role of protriptyline in treating sleep apnoea. However, these preliminary reports indicate that a carefully monitored trial of protriptyline may benefit selected patients with mild to moderate obstructive sleep apnoea. Since beneficial effects from the drug develop slowly, the trial should last at least three weeks. We do not recommend this pharmacological treatment in severe cases of sleep apnoea because any delay in performing a necessary tracheostomy increases the risk of sudden death.

We acknowledge gratefully the technical editing and assistance of Dr Patricia Cornett.

\section{References}

${ }^{1}$ Guilleminault C, Van den Hoed J, Mitler M. Clinical overview of the sleep apnoea syndromes. In: Guilleminault $C$, Dement WC, eds. Sleep apnoea syndromes. New York: Alan R Liss, 1978: 1.

${ }^{2}$ Sauerland EK, Harper RM. The human tongue during sleep. Electromyographic activity of the genioglossus muscle. Exp Neurol 1976;51:160-70.

${ }^{3}$ Weitzman E, Pollack CP, Borowiecki B, Burack B, Shprintzen R, Rakoff $S$. The hypersomnia-sleep apnoea syndrome: site and mechanism of upper airway obstruction, In: Guilleminault C, Dement WC, eds. Sleep apnoea syndromes. New York: Alan R Liss, 1978: 235.

${ }^{4}$ Sackner M, Landa J, Forrest T, Greeneltch D. Periodic sleep apnoea: chronic sleep deprivation related to intermittent upper airway obstruction and central nervous system disturbance. Chest 1975;67:164-71.

${ }^{5}$ Simmons FB, Guilleminault D, Dement WC, Tilkian AG, Hill M. Surgical management : of airway obstruction during sleep. Laryngoscope 1977;87:326-38. 
- Conway WA, Victor LD, Magilligan DJ, et al. Adverse effects of tracheostomy for sleep apnoea. JAMA 1981; 246:347-50.

7 Schmidt HS, Clark RW, Hyman PR. Protriptyline: an effective agent in the treatment of the narcolepsycataplexy syndrome and hypersomnia. Am J Psychiatry 1977;134:183-5.

${ }^{8}$ Conway W, Fujita S, Zorick F, Roth T, Hartse A, Piccione $P$. Uvulopalatopharyngoplasty in treatment of upper airway sleep apnoea. Am Rev Respir Dis 1980;121: (Abstr) 121.

${ }^{9}$ Rechtschaffen A, Kales A, eds. A manual of standardised terminology, techniques and scoring system for sleep stages of human subjects. Bethesda: National Institutes of Health, Publication No 204, 1968.

${ }^{10}$ Suiton FD, Zwillich CW, Creagh CE, Pierson DJ, Weil JV. Progesterone for outpatient treatment of Pickwickian Syndrome. Ann Intern Med 1975;83:476-9.

${ }^{11}$ Lugaresi E, Coccagna C, Mantovani M. Hypersomnia with periodic apnoeas. Jamaica: Spectrum Publications Medical and Scientific Books, 1978:113-4.

12 Orr WC, Imes NK, Martin RJ. Progesterone therapy in obese patients with sleep apnoea. Arch Intern Med 1979;
$139: 109-11$.

${ }^{13}$ Kumashiro H, Sato M, Hirata J, Baba O, Orsuki S. Sleep apnoea and sleep regulating mechanism: a case effectively treated with monochlorimipramine. Folia Psychiatr Neurol Jpn 1971 ;25:42-9.

14 Schwartz BA, Rochemaure J. Syndrome pickwickien: traitement par la chlorimipramine. Nouv Presse Med 1973;2:1520.

15 Clark RW, Schmidt HS, Schaal SF, Boudoulas H, Schuller DE. Sleep apnoea: treatment with protriptyline. Neurol $1979 ; 29: 1287-92$.

16 Krieger J, Mangin P, Kurtz D. Sleep apnoea syndrome: effects of chlorimipramine in subjects with stable body weight. Rev Electroencephalogr Neurophysiol Clin 1979; 9:250-7.

17 Tilkian AG, Guilleminault C, Schroeder JS, Lehrman KL, Simmons FB, Dement WC. Sleep-induced apnoea syndrome. Am J Med 1977;63:348-58.

${ }^{18}$ Carlsson A, Corrodi H, Fuxe K, Hökfelt F. Effects of some antidepressant drugs on the depletion of intraneuronal brain catecholamine stores caused by 4-alpha-dimethylmeta-tyramine. Eur J Pharmacol 1968/69;5:367-73. 